\title{
Isolated Histoplasmosis of Tongue: A Case Report with Review of the Literature
}

\author{
J Gulia, . Yadav, A Hooda
}

\section{Citation}

J Gulia, . Yadav, A Hooda. Isolated Histoplasmosis of Tongue: A Case Report with Review of the Literature. The Internet Journal of Dermatology. 2010 Volume 8 Number 2.

\begin{abstract}
Histoplasmosis is a systemic fungal disease. Oral histoplasmosis usually occurs in association with the chronic disseminated form of the disease and isolated oral presentation is rare. A case of isolated histoplasmosis involving the tongue in a HIVnegative patient is being reported.
\end{abstract}

\section{INTRODUCTION}

The clinical picture of histoplasmosis ranges from asymptomatic infection to life-threatening illness depending upon the intensity of the exposure, immune status of the individual, and the lung architecture of the host. Progressive disseminated histoplasmosis is typically seen in immunocompromised individuals. Common risk factors include acquired immune deficiency syndrome, extremes of age, and anti-TNF- $\square$ agents. ${ }^{1}$ The muco-cutaneous lesions are rare and should always be considered a manifestation of disseminated disease. ${ }^{2}$ A case of isolated tongue histoplasmosis in a HIV negative patient is being presented.

\section{CASE REPORT}

A 40 years old male patient presented with ulcer on the tongue of three months duration. The ulcer was slowly increasing in size and was associated with pain, odynophagia and some difficulty in speech. There was no history of travel to farm or caves. There was no history of oral trauma. He was non-alcoholic, non-smoker, non-diabetic. Past history was negative for tuberculosis.

The general physical examination was normal. Examination of oral cavity revealed poor oro-dental hygiene. A large ulcer of size $1.2 \times 2.6 \mathrm{~cm}$. was seen on the base of the tongue. Another small ulcer of size $0.7 \times 0.7 \mathrm{~cm}$ was also noticed near the tip on the dorsal surface on the left side of midline of the tongue. The margins of the ulcer were raised and edematous. The floor of the ulcer was covered with thick secretions. On palpation, the ulcer was tender and indurated. (Fig 1)

\section{Figure 1}

Figure 1: Showing lesions on the base of the tongue and near the tip on the dorsal surface on the left side of midline of the tongue.

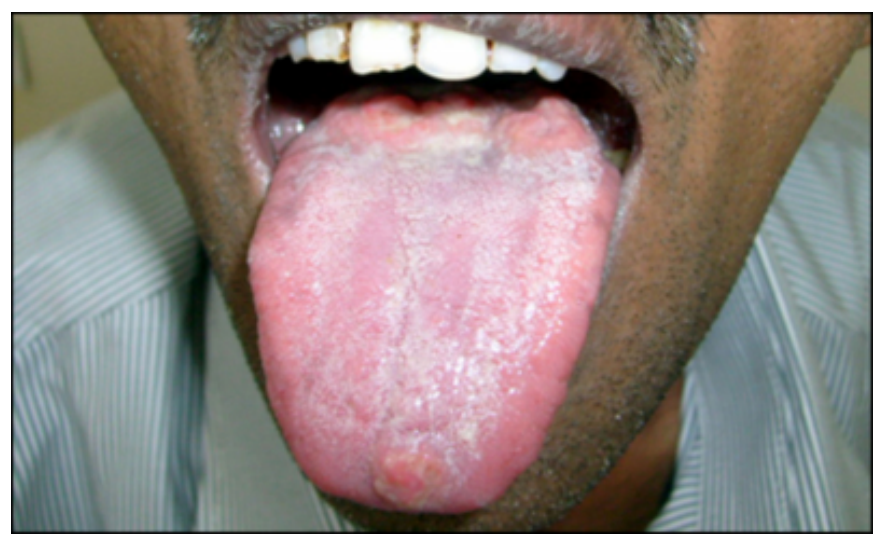

The patient was investigated. Hematological examination was normal. X-ray chest PA view and ultrasound whole abdomen were normal. HIV test was negative. A biopsy was taken from one of the ulcers which revealed the evidence of histoplasmosis. The patient was started on oral Itraconazole $200 \mathrm{mg}$ thrice a day for three days followed by twice daily for 12 months after obtaining baseline SGOT and SGPT levels. The patient was advised to follow up regularly.

\section{DISCUSSION}

Histoplasmosis was first described by Darling (1905) while working in the Canal Zone in Panama. He described the disseminated form of the disease in a fatal case from Martinnique. $^{3}$

Histoplasmosis has been reported worldwide but it is more prevalent in certain parts of North and Central America. The 
Ohio and Mississippi river valleys are known to be endemic for histoplasmosis since 1945. A moderate climate, humidity and soil characteristics may be responsible for endemicity. Bird and bat droppings/excrement enhances the growth of the organism in soil by accelerating sporulation. ${ }^{4-7}$

There are two varieties of $\mathrm{H}$. capsulatum which are pathogenic to humans: $H$. capsulatum variety capsulatum and $H$. capsulatum variety duboisii. A third variety named $H$. capsulatum variety farciminosum is an equine pathogen. ${ }^{4}$ Soil containing large amount of bird or bat guano, especially which is found under roosts or next to chicken coops, supports growth of the mold. ${ }^{5}$ Once the soil is contaminated it yields $H$. capsulatum for many years even after birds no longer roost in the area. Caves can be highly contaminated by $H$. capsulatum that thrives on the bat guano. ${ }^{6}$

H. Capsulatum exposure is very common for persons living in areas of endemicity, but symptomatic infection is uncommon. ${ }^{4}$ The clinical manifestations occur in a small number (less than 1\%) and vast majority of infected persons have either no symptoms or a very mild illness. Acute pulmonary histoplasmosis is a self limiting disease. Patient may have fever, malaise, headache, weakness and dry cough. ${ }^{8}$ It may be accompanied by rheumatologic and/or dermatologic manifestations in about $5 \%$ of patients. ${ }^{9}$ In patients with decreased cell mediated immunity, the pulmonary infection will frequently progress to involve multiple lobes and acute respiratory distress can occur. ${ }^{10}$ Immunocompromised patients and cases with decreased cell mediated immunity include patients with AIDS, transplant recipients, those with hematologic malignancies and those on corticosteroids. ${ }^{11-13}$ Patients with CD4 counts of less than 150 cells/ $\mu \mathrm{l}$ are at increased risk. ${ }^{14-16}$

Mucous membrane lesions are seen in disseminated histoplasmosis. The tongue, gingival and buccal mucosa, lips, pharynx and larynx can be involved. Superficial ulcerations, deep ulcerations with heaped-up borders, nodular masses and verrucous lesions can occur. Although localized oral lesions in patients with no other symptoms of disseminated infection have been described this is very uncommon and muco-cutaneous lesions should always be considered a manifestation of disseminated disease. Goodwin et al stated that the most characteristic lesion in chronic disseminated histoplasmosis is an oro-pharyngeal ulcer and it occurs in about $70 \%$ of the cases ${ }^{10}$. Antonello et al suggested that oral histoplasmosis is the first sign of disseminated histoplasmosis ${ }^{17}$.
The oral ulcers have a rolled up edges suggesting malignancy as was seen in our case also. The clinical manifestations in the cases of histoplasmosis known from India appears to be predominant occurrence of mucocutaneous lesions in the oral cavity with liver spleen and lungs being involved only in $35 \%$ of the cases. ${ }^{18-21}$

Fungal culture remains the gold standard diagnostic test for H. capsulatum. It can be grown on Sabouraud dextrose agar incubated at 25 degree Celsius. After several weeks may be up to six weeks, growth of a white to light tan mold occurs. Two types of conidia are produced on the hyphae: macroconidia and the microconidia. ${ }^{22}$ Fungal stains of cytopathology or biopsy materials showing structures resembling histoplasma yeast are helpful in the diagnosis. On tissues biopsy distinctive 2-4 micro meter oval, narrow based budding yeasts are seen and a tentative diagnosis can be made. ${ }^{23,24}$ Tissue should be stained in methenamine silver or periodic acid-Schiff stains to best visualize $H$. capsulatum. Yeasts are typically found within the macrophages but can also be seen free in tissues.

The proven antifungal agents for the treatment of histoplasmosis include amphotericin $\mathrm{B}^{25}$, liposomal amphotericin $\mathrm{B}^{26}$, amphotericin $\mathrm{B}$ liquid complex ${ }^{27}$ and itraconazole $^{28,29}$. Amphotericin B formulations are used for patients who have severe pulmonary or disseminated forms of histoplasmosis. Presently, except for children, for whom a one month course of amphotericin B deoxycholate is usually curative, it is rare to give amphotericin B for the entire course of therapy and it is given initially until the patient has shown a favorable response and can take an oral antifungal agents: then, itraconazole is given for the remainder of the treatment course. ${ }^{30,31}$ For mild to moderate form of progressive disseminated histoplasmosis itraconazole (200 mg 3 times daily for three days and then twice daily, as guided by determination of the blood concentration levels of itraconazole) for at least 12 months is recommended ${ }^{28}$.

The azoles exert antifungal activity by inhibiting fungal cytochrome P450 3A 4- dependent enzyme lanosterol 14-】demethylase. Itraconazole given orally is preferred for patients who have mild to moderate histoplasmosis and further its uses as a step down therapy after an initial response with amphotericin $\mathrm{B} .^{29}$ Fluconazole is less effective than itraconazole in treatment of histoplasmosis. Clinical data on the new azoles, voriconazole and posaconazole, for the treatment of histoplasmosis are limited; though both agents have activity in vitro against $\mathrm{H}$. capsulatum. ${ }^{30,32}$ 
Both posaconazole ${ }^{33}$ and voriconazole ${ }^{34,35}$ have been used successfully in a smaller number of patients with a variety of different forms of histoplasmosis. The azoles may be hepatotoxic and hepatic enzymes levels should be measured before therapy is started and at least on 1,2 and 4 weeks and every 3 months during therapy.

\section{References}

1. Hage CA, Wheat LJ. Histoplasmosis. In Fauci AS, Braunwald E, Hauser SL, Kasper DL, Longo DL, Jameson JL (Eds) Harrison's Principle internal medicine 2008,. McGraw Hill, New York, NY 17th ed: p 1244-47.

2. Corcoran GR, Al-Abdely H, Flanders CD, Geimer J, Patterson TF. Markedly elevated serum lactate dehydrogenase levels are a clue to the diagnosis of disseminated histoplasmosis in patients with AIDS. Clin Infect Dis1997 24:942-44.

3. Darling ST. A protozoan general infection producing pseudo-tubercles in the lungs and focal necroses in the liver, spleen, and lymph nodes. JAMA 1906; 46:1283-85.

4. Kauffman CA. Histoplasmosis. In Dismukes WE, Pappas PG, Sobel JD (eds.), Clinical mycology 2003. Oxford

University Press, New York, NY: p. 285-98.

5. Cano M, Hajjeh RA. The epidemiology of histoplasmosis: a review. Semin Respir Infect 2001; 16:109-118.

6. Lottenberg O, Waldman RH, Ajello L, Hoff GL, Bigler W, Zellner SR. Pulmonary histoplasmosis associated with exploration of a bat cave. Am J Epidemiol 1979;

110:156-161

7. Jones TF, Swinger GL, Craig AS, McNeil MM, Kaufman $\mathrm{L}$, Schaffner W. Acute pulmonary histoplasmosis in bridge workers: a persistent problem. Am J Med 1999; 106:480-82. 8. Goodwin RA Jr., Loyd JE, des Prez RM. Histoplasmosis in normal hosts. Medicine 1981; 60:231-66.

9. Medeiros AA, Marty SD, Tosh FE, Chin TDY. Erythema nodosum and erythema multiforme as clinical manifestations of histoplasmosis in a community outbreak. N Engl J Med 1966; 274:415-20.

10. Goodwin RA Jr, Shapiro JL, Thurman GH, Thurman SS, des Prez RM. Disseminated histoplasmosis: clinical and pathological correlations. Medicine 1980; 59:1-33.

11. Johnson PC, Khardori N, Najjar AF, Butt F, Mansell PWA, Sarosi GA. Progressive disseminated histoplasmosis in patients with the acquired immunodeficiency syndrome. Am J Med 1988; 85:152-58.

12. Burke DG, Emancipator SN, Smith MC, Salata RA. Histoplasmosis and kidney disease in patients with AIDS. Clin Infect Dis 1997; 25:281-84.

13. Freifeld AG, Iwen PC, Lesiak BL, Gilroy RK, Stevens RB, Kalil AC. Histoplasmosis in solid organ transplant recipients at a large Midwestern university transplant center. Transpl Infect Dis 2005; 7:109-15

14. Clark B, Foster R, Tunbridge A, Green S. A case of disseminated histoplasmosis successfully treated with the investigational drug posaconazole. J Infect 2005. 51:177-80. 15. Gutierrez ME, Canton A, Sosa N, Puga E, Talavera L. Disseminated histoplasmosis in patients with AIDS in Panama: a review of 104 cases. Clin Infect Dis 2005; 40:1199-1202

16. McKinsey DS, Spiegel RA, Hutwanger L, Stanford J, Driks MR, Brewer J et al. Prospective study of histoplasmosis in patients infected with human immunodeficiency virus: incidence, risk factors, and pathophysiology. Clin Infect Dis 1997; 24:1195-1203.

17. Antonello VS, Zaltron VF, Vial M, Oliveira FM, Severo
C. Oropharyngeal histoplasmosis: report of eleven cases and review of the literature. Rev Soc Bras Med Trop 2011 Feb;44(1):26-9.

18. Mignogna, MD, Fedele S, Lo Russo L, Ruoppo E, Lo Muzio L. A case of oral localized histoplasmosis in an immunocompetent patient. J Clin Microbiol Infect. Dis 2001; 20:753-55

19. Randhawa HS, Khan ZU. Histoplasmosis in India: Current status. Indian J Chest Dis Allied Sci 1994;36:193-213.

20. Padhyae AA, Pathak AA, Katyar VJ, Hazare VK, Kaufman L. Oral histoplasmosis in India: Case report and overview of the cases reported during 1968-1992. J Med Vet Mycol 1994;32: 93-103.

21. Subramanian S, Abrham OC, Rupali P, Zachariah A, Mathews MS, Mathai D. Disseminated histoplasmosis. J Assoc Physicians India 2005; 53:185-9.

22. Davis A, Pierson D, Loyd JE. Mediastinal fibrosis.

Semin Respir Infect 2001. 16:119-130.

23. Paya CV, Roberts GD, Cockerill FR III. Laboratory methods for the diagnosis of disseminated histoplasmosis: clinical importance of the lysis-centrifugation blood culture technique. Mayo Clin Proc 1987; 62:480-85.

24. Schuster TG, Hollenbeck BK, Kauffman CA, Chensue SW, Wei JT. Testicular histoplasmosis. J. Urol 2000; 164:1652.

25. Sarosi GA, Voth DW, Dahl BA, Doto IL, Tosh FE.

Disseminated histoplasmosis: results of long】term follow $\backslash u p$ : a Center for Disease Control cooperative mycoses study. Ann Intern Med 1971; 75:511-16.

26. Johnson PC, Wheat LJ, Cloud GA, Goldman M, Lancaster D, Bamberger DM et al. Safety and efficacy of liposomal amphotericin B compared with conventional amphotericin B for induction therapy of histoplasmosis in patients with AIDS. Ann Intern Med 2002; 137:105-9. 27. Perfect JR. Treatment of non $\llbracket$ aspergillus moulds in immunocompromised patients, with amphotericin B lipid complex. Clin Infect Dis 2005; 40(Suppl 6):S401-8.

28. Wheat LJ, Freifeld AG, Kleiman MB, Baddley JW, McKinsey DS, Loyd JE et al. Clinical practice guidelines for the management of patients with Histoplasmosis: 2007 update by the infectious disease society of America. Clin Infect Disease 2007; 45: 807-25.

29. Dismukes WE, Bradsher RW Jr, Cloud GC, Kauffman CA, Chapman SW, George RB et al. Itraconazole therapy for blastomycosis and histoplasmosis. NIAID Mycoses Study Group. Am J Med 1992; 93:489-97.

30. Kohler S, Wheat LJ, Connolly P, Schnizlein-Bick C, Durkin M, Smedema M et al. Comparison of the echinocandin caspofungin with amphotericin B for treatment of histoplasmosis following pulmonary challenge in a murine model. Antimicrob Agents Chemother 2000; 44:1850-4.

31. Wheat J, Hafner R, Korzun AH, Limjoco MT, Spencer $\mathrm{P}$, Larson RA et al. Itraconazole treatment of disseminated histoplasmosis in patients with the acquired immunodeficiency syndrome. AIDS Clinical Trial Group. Am J Med 1995; 98:336-42.

32. Al\Agha OM, Mooty M, Salarieh A. A 43』year】old woman with acquired immunodeficiency syndrome and fever of undetermined origin: disseminated histoplasmosis. Arch Pathol Lab Med 2006; 130:120-3.

33. Restrepo A, Tobon A, Clark B, Graham DR, Corcoran G, Bradsher RW et al. Salvage treatment of histoplasmosis with posaconazole. J Infect 2007; 54:319-27.

34. Smith J, Safdar N, Knasinski V, Simmons W, Bhavnani SM, Ambrose PG et al. Voriconazole therapeutic drug monitoring. Antimicrob Agents Chemother 2006; 
50:1570-2.

35. Leveque D, Nivoix Y, Jehl F, Herbrecht R. Clinical pharmacokinetics of voriconazole. Int J Antimicrob Agents 2006; 27:274-84. 


\section{Author Information}

Joginder Singh Gulia, MS Otorhinolaryngology

Professor, Department of Otorhinolaryngology, Pt. B.D Sharma University of Health Sciences

. Samar Pal Singh Yadav, MS Otorhinolaryngology

Senior Professor, Department of Otorhinolaryngology, Pt. B.D Sharma University of Health Sciences

Anita Hooda, MDS

Associate Professor, Department of Oral Anatomy, Pt. B.D Sharma University of Health Sciences 